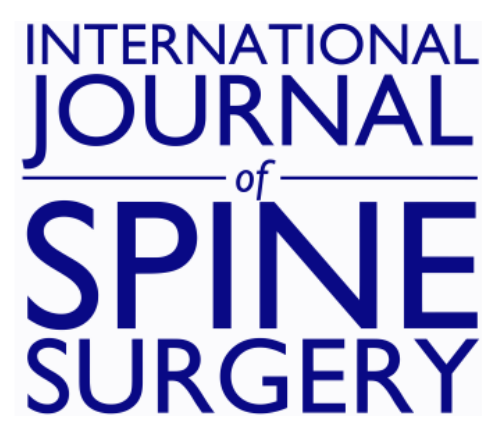

\title{
Demographic Analysis of Pedicle Diameter, and Estimated Pedicle Screw Length of the Lumbar Spine in a Diverse Population
}

Brandon Petrone, Joseph Albano, Robert Stockton, Aaron M. Atlas, Courtney Aronica and Kanwarpaul Grewal

Int J Spine Surg 2021, 15 (2) 259-265

doi: https://doi.org/10.14444/8035

http://ijssurgery.com/content/15/2/259

This information is current as of April 26, 2023.

Email Alerts Receive free email-alerts when new articles cite this article. Sign up at: http://ijssurgery.com/alerts 


\title{
Demographic Analysis of Pedicle Diameter, and Estimated Pedicle Screw Length of the Lumbar Spine in a Diverse Population
}

\author{
BRANDON PETRONE, DO, JOSEPH ALBANO, DO, ROBERT STOCKTON, DO, AARON M. ATLAS, DO, \\ COURTNEY ARONICA, BA, KANWARPAUL GREWAL, DO \\ Department of Orthopedic Surgery, Northwell Health Plainview Hospital, Plainview, New York
}

\begin{abstract}
Background: Recent literature confirms the importance of understanding the variability in pedicle morphology among races. These studies suggest that more detailed and reliable measurements of pedicles should be undertaken. However, there is limited data on average pedicle diameters (PDs) or estimated pedicle screw lengths (EPSLs) between diverse racial populations. We sought to determine the differences in PD and EPSL in the lumbar spine between various races: "Asian," "Black," "White," and "Hispanic" to aid in perioperative planning during instrumented spinal fusion.

Methods: Axial cuts of 404 patients were inspected to obtain their transverse outer cortical PD as measured through the isthmus, and EPSL by measuring the posterior entry point at the longest distance, which perpendicularly transected the measured isthmic diameter, to the anterior vertebral cortex from L1 to L5. We examined the average PD and PD range at each level for each race. To determine the significance, we used a mixed analysis of variance and a post hoc analysis.

Results: In this retrospective chart review the races were found to be significantly different in PD and EPSL $(P<$ .001). Post hoc analysis using Dunn-Bonferroni correction showed that Asians had significantly smaller PDs than Blacks and Whites $(P<.002$ and $P<.014$, respectively). The White and Hispanic population had significantly longer EPSLs when compared to Blacks and Asians from L1 to L5 $(P<.01)$.

Conclusions: This study demonstrates that there are significant differences in pedicle morphology among races that must be taken into consideration when inserting pedicle screws during lumbar spinal fusion. Knowledge of these differences is of the utmost importance in order to limit complications while improving fixation.
\end{abstract}

Level of Evidence: 3.

Clinical Relevance: Pedicle morphology is variable between races and understanding these differences is important for the safe placement of pedicle screws.

Lumbar Spine

Keywords: pedicle screws, spine, osteology, demographics

\section{INTRODUCTION}

A thorough understanding of bone anatomy is of the utmost importance when performing instrumented postero-lateral lumbar fusion. Better understanding of anatomic variability offers to improve patient safety by increasing the surgeon's accuracy when selecting pedicle screws during instrumentation. Generally, pedicle screw size and length is estimated intraoperatively and by surgeon preference and experience for all patients. Subtle deviations in the placement of instrumented hardware can lead to pedicle screw cortical breach and catastrophic patient complications relating to neu- rovascular compromise or deformity, necessitating repeat operations. ${ }^{1,2}$

There have been several studies that have analyzed the morphometry of pedicles in the lumbar spine between races. ${ }^{3,4}$ Each study demonstrated significant pedicle variability in the lumbar spine among different races; emphasizing the need for preoperative planning when performing pedicle screw fixation.

It has been well established in the literature that the Asian population has significantly smaller pedicles when compared to other races. ${ }^{3,5-8}$ Yusof et $\mathrm{al}^{5}$ examined transpedicular screw fixation for the cervical spine in the Malaysian population and recommended a preoperative computed tomogra- 
phy (CT) scan because of their significantly smaller pedicle diameters (PDs). Albano et $\mathrm{al}^{3}$ recently performed an extensive review of PD among different races and were able to demonstrate that the Asian population has significantly smaller lumbar PDs when compared to other races. However, the outer cortical PD was measured only in the coronal plane. Simpson et $\mathrm{al}^{9}$ determined that the outer cortical pedicle width measurement on the coronal view alone could overestimate the true pedicle width and therefore multiple planes need to be examined to obtain the true value. Unfortunately these studies are incomplete and fail to evaluate the differences in estimated pedicle screw length (EPSL). To our knowledge, however, there has not been an extensive review of EPSL among different races.

Lumbar spine fusion is more difficult to achieve in osteoporotic bone than in healthy bone, ${ }^{10}$ and gaining adequate screw purchase can be difficult. ${ }^{11}$ Misenhimer et $\mathrm{al}^{12}$ had progressively loaded cadaveric pedicles and found that plastic deformity of the pedicles preceded fracture when the screw threads were larger than the endosteal diameter or were within $80 \%$ of the outer cortical diameter. Therefore, approximately $80 \%$ of the measured cortical diameter is the maximum safe width into which a pedicle screw can be inserted. Therefore, both pedicle screw diameter and length are important for safe screw placement, ${ }^{1,2}$ and to maximize pullout strength. ${ }^{13,14}$ However, the exact diameter and length of the vertebral pedicle is rarely measured prior to screw insertion. This shortcoming is primarily due to the difficulty of obtaining this measurement in situ. In this study, we discuss the inherent variability related to patient demographics in pedicle morphology as it relates to PD and EPSL, and the potential benefits of understanding and predicting pedicle variation.

Overall, the current literature suggests tremendous variability of pedicle morphology and that improper pedicle screw selection could lead to significant morbidity and cost. Therefore, a more thorough understanding of the relationship between pedicles and race could aid in pedicle screw selection. Thereby improving outcomes and reducing morbidity. The purpose of this study was to determine the differences in PD and EPSL in the lumbar spine between various races: "Asian," "Black," "White," and "Hispanic." We hypothesized that there would be a significant difference between the average lumbar spine PD and EPSL among individual races.

\section{MATERIALS AND METHODS}

Approval from our health system's Institutional Review Board was obtained to investigate the hypothesis that there is a significant difference between the average lumbar spine PD and EPSL of individual races. It was determined that due to the low risk and retrospective nature of the study, informed consent would not be needed. A retrospective review of all CT scans of the abdomen and pelvis that were performed over a 2-week period (between July 1, 2016, and July 14, 2016) at 7 hospitals within a single health system was analyzed for the purpose of this study. Using abdominal and pelvic studies rather than lumbar spine scans allowed us to screen a large and diverse population of patients who presented with chief complaints not related to back pain and, therefore, without any vertebral pathology that could potentially alter the geometry of a pedicle. Further exclusion criteria were established to exclude patients with other vertebral factors that could alter pedicle geometry.

Axial and sagittal cuts of the lumbar spine from L1 to L5 bilaterally were inspected to obtain their outer cortical PD as measured through the isthmus on axial views, which perpendicularly transected the pedicle on sagittal view. EPSL was determined by measuring the posterior entry point at the longest distance that perpendicularly transected the measured isthmic diameter to the anterior vertebral body cortex (Figure 1). If present, the mamillary process was used as the starting point for pedicle screw length measurement. Sagittal reference images were set to correlate parallel to the end plates of the corresponding vertebrae. The sagittal plane was set $90^{\circ}$ relative to the axial plane to ensure consistent measurement parameters, notwithstanding anatomic variations inherent in subtle deformity or positional discrepancies. Bone window CT images were selected for all measurements to allow for a sharp contrast between cortices and soft tissue. The standard General Electric picture archiving and communication systems (PACS; General Electric Medical Systems, Milwaukee, Wisconsin) measuring tool was used for all measurements (Figure 1). Measurements were performed by 3 readers using the standard methods described above.

Patients were excluded if they had prior lumbosacral laminectomy or fusion, CT imaging that did 


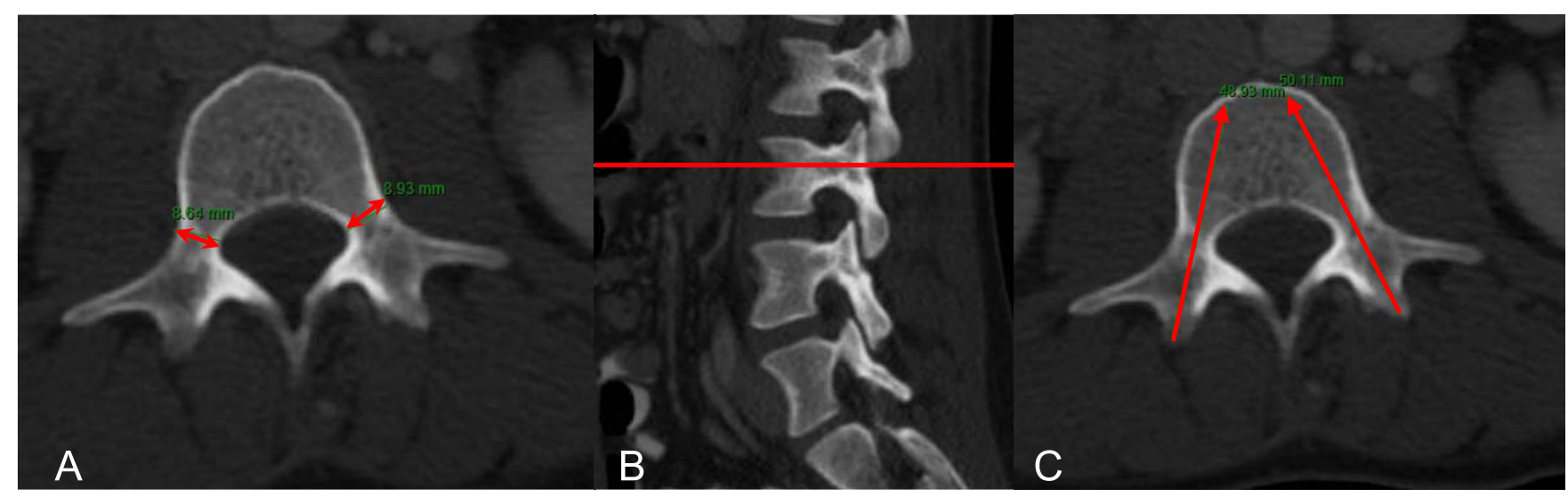

Figure 1. Measurement technique. Demonstration of the measurement technique for outer cortical pedicle diameter $(A, B)$, and estimated pedicle screw length $(C)$.

not allow for visualization of all 5 lumbar segments, scoliosis involving the lumbar vertebrae with Cobb measurement angle greater than $20^{\circ}$, or spondylolisthesis having greater than $25 \%$ slippage. Data were collected and categorized on the basis of patient-reported racial information, race was categorized as Asian, Black, White, and Hispanic.

\section{Statistical Methods}

Patient demographic information, including age, gender, and body mass index (BMI), was collected from a retrospective chart review. Descriptive statistics between races was computed and reported as mean (standard deviation) and frequency (percentage of total cohort). Comparative analysis between groups of different races was conducted using 1-way analysis of variance (ANOVA) testing followed by post hoc pairwise comparisons using Dunn-Bonferroni corrections. ANOVA testing was first performed to measure significant differences in demographic variables between groups. To account for differences in these variables, which could potentially confound the outcomes of pedicle dimensions, any factor which differed significantly between ethnicity groups was subsequently controlled for as a covariate using an analysis of covariance (ANCOVA) model. In this model, missing subject demographic values were populated with the average variable value for the respective ethnicity and gender group of the subject. All analyses were performed using SPSS (version 22.0, IBM Corp., Armonk, New York). $P$ values were 2tailed with $P<.05$ considered statistically significant.

\section{RESULTS}

Of the 404 patients that met the inclusion criteria, the demographic breakdown yielded 141 Black (35\%), 105 White $(26 \%), 86$ Asian $(21 \%)$, and 72 Hispanic (18\%) (Table 1). The average age of the total study population was 56 years old with a range of 16 to 96 years old (Table 1 ).

The races were found to be significantly different in PD at all levels $(P<.001)$. After controlling for covariates, only L5 was no longer significant between races (Table 2). The average transverse isthmic outer cortical PD from L1 to L3 was found to be largest in the Black population. At lumbar pedicles L4 and L5, the White population was found to have the largest PD. The Asian population was found to have the smallest PD at all levels (Table 3). Pairwise comparisons using ANCOVA and DunnBonferroni correction showed that Asians had significantly smaller PDs than Blacks and Hispanics $(P<.001$ and $P<.047$, respectively) (Table 4).

We evaluated the ranges to examine the variability and outliers within races. The range of pedicle size was also inspected at each level for each group

Table 1. Study population demographics including gender, age, and body mass index (BMI) separated by race.

\begin{tabular}{|c|c|c|c|c|c|c|c|c|}
\hline Race & No. of patients & Male & Female & Mean Age, y & Age Range & Mean Height $\pm \mathrm{SD}, \mathrm{cm}$ & Mean Weight $\pm \mathrm{SD}, \mathrm{kg}$ & Mean BMI $\pm \mathrm{SD}, \mathrm{kg} / \mathrm{m}^{2}$ \\
\hline Black & 141 & 43 & 98 & 54.4 & 19 to 98 & $167.2 \pm 8.8$ & $77.2 \pm 16.2$ & $27.6 \pm 5.3$ \\
\hline White & 105 & 49 & 56 & 63.9 & 17 to 97 & $167.7 \pm 8.9$ & $83.9 \pm 18.6$ & $29.5 \pm 6.2$ \\
\hline Asian & 86 & 48 & 38 & 53.5 & 16 to 90 & $166.8 \pm 7.5$ & $70.9 \pm 16.1$ & $25.2 \pm 4.3$ \\
\hline Hispanic & 72 & 37 & 35 & 48.9 & 17 to 94 & $166.0 \pm 7.7$ & $78.8 \pm 11.6$ & $29.1 \pm 3.2$ \\
\hline Total & 404 & 177 & 227 & 55.7 & 16 to 98 & $167.0 \pm 8.3$ & $77.9 \pm 16.7$ & $27.9 \pm 5.3$ \\
\hline
\end{tabular}


Table 2. One-way analysis of variance (ANOVA) and analysis of covariance (ANCOVA) tests of between-group effects.

\begin{tabular}{|c|c|c|c|c|c|c|}
\hline \multirow[b]{2}{*}{ Factor } & \multicolumn{3}{|c|}{$\mathbf{A N O V A}^{\mathrm{a}}$} & \multicolumn{3}{|c|}{$\mathrm{ANCOVA}^{\mathrm{b}}$} \\
\hline & Sum of Squares & Mean Square & $\boldsymbol{P}$ & Sum of Squares & Mean Square & $\boldsymbol{P}$ \\
\hline Age & 10912.8 & 3637.6 & $<.001^{\mathrm{cc}}$ & $\mathrm{N} / \mathrm{A}^{\mathrm{d}}$ & $\mathrm{N} / \mathrm{A}$ & $\mathrm{N} / \mathrm{A}$ \\
\hline BMI & 1005.6 & 335.2 & $<.001^{\mathrm{c}}$ & $\mathrm{N} / \mathrm{A}$ & $\mathrm{N} / \mathrm{A}$ & $\mathrm{N} / \mathrm{A}$ \\
\hline Height & 133.2 & 44.4 & .600 & $\mathrm{~N} / \mathrm{A}$ & $\mathrm{N} / \mathrm{A}$ & $\mathrm{N} / \mathrm{A}$ \\
\hline Weight & 8143.8 & 2714.6 & $<.001^{\mathrm{c}}$ & $\mathrm{N} / \mathrm{A}$ & $\mathrm{N} / \mathrm{A}$ & $\mathrm{N} / \mathrm{A}$ \\
\hline Pedicle Width, mm (total) & 40.6 & 13.5 & $.001^{\mathrm{c}}$ & 33.2 & 11.1 & $.001^{\mathrm{c}}$ \\
\hline L1 & 87.2 & 29.1 & $<.001^{\mathrm{c}}$ & 83.5 & 27.8 & $<.001^{\mathrm{c}}$ \\
\hline L2 & 33.6 & 11.2 & $.005^{\mathrm{c}}$ & 37.2 & 12.4 & $.001^{\mathrm{c}}$ \\
\hline L3 & 33.5 & 11.2 & $.014^{\mathrm{c}}$ & 28.3 & 9.4 & $.011^{\mathrm{c}}$ \\
\hline L4 & 44.7 & 14.9 & $.004^{\mathrm{c}}$ & 35.2 & 11.7 & $.005^{\mathrm{c}}$ \\
\hline L5 & 49.8 & 16.6 & $.011^{\mathrm{c}}$ & 29.2 & 9.7 & .051 \\
\hline Pedicle Length, mm (total) & 2316.4 & 772.1 & $<.001^{\mathrm{c}}$ & 1924.3 & 641.4 & $<.001^{\mathrm{c}}$ \\
\hline L1 & 3703.9 & 1234.6 & $<.001^{\mathrm{c}}$ & 3095.3 & 1031.8 & $<.001^{\mathrm{c}}$ \\
\hline L2 & 3233.2 & 1077.7 & $<.001^{\mathrm{c}}$ & 2717.7 & 905.9 & $<.001^{\mathrm{c}}$ \\
\hline L3 & 2255.9 & 752.0 & $<.001^{\mathrm{c}}$ & 1962.1 & 654.0 & $<.001^{\mathrm{c}}$ \\
\hline L4 & 1521.5 & 507.2 & $<.001^{\mathrm{c}}$ & 1287.5 & 429.2 & $<.001^{\mathrm{c}}$ \\
\hline L5 & 1454.0 & 484.7 & $<.001^{\mathrm{c}}$ & 1108.4 & 369.5 & $<.001^{\mathrm{c}}$ \\
\hline
\end{tabular}

Abbreviations: BMI, body mass index; N/A, not applicable.

${ }^{a}$ ANOVA showing significant differences between ethnicity groups in age, BMI, weight, pedicle width (L1-L5) and length (L1-L5).

${ }^{\mathrm{b}}$ ANCOVA demonstrates significant differences in pedicle width and length persist despite controlling for age, BMI, and weight covariates.

'Significant: $P<.05$.

${ }^{\mathrm{d} N}$ /A: Result not applicable as variable is either being controlled (age, BMI, weight) or not applied (height) within the ANCOVA model.

studied (Table 3). The data obtained highlighted the significant variability between individuals. The lowest range at any level was $6.3 \mathrm{~mm}$ (found in the Asian group at L1). The largest range was found in the Black population at $\mathrm{L} 3(10.7 \mathrm{~mm})$. The widest range was observed in the Black population at levels
L1 and L3-L5. At L2, the White group range was greatest and slightly larger than the Black group.

The races were found to be significantly different in EPSL at all levels $(P<.001)$. EPSL remained significant at all levels after controlling for covariates (Table 2). Pairwise comparisons using

Table 3. Lumbar pedicle widths and lengths by race.

\begin{tabular}{|c|c|c|c|c|c|}
\hline Pedicle & Race & Mean Width $\pm \mathrm{SD}, \mathrm{mm}$ & $\begin{array}{c}\text { Mean Width } \\
\text { Smallest-Largest, mm }\end{array}$ & Mean Length $\pm \mathrm{SD}, \mathrm{mm}$ & $\begin{array}{c}\text { Mean Length } \\
\text { Smallest-Largest, mm }\end{array}$ \\
\hline \multirow[t]{5}{*}{$\mathrm{L} 1$} & Black & $7.8 \pm 1.7$ & $3.7-13.2$ & $48.4 \pm 4.1$ & $39.5-58.4$ \\
\hline & White & $7.2 \pm 1.7$ & $4.3-12.5$ & $55.2 \pm 4.5$ & $44.0-67.1$ \\
\hline & Asian & $6.6 \pm 1.4$ & $3.9-10.2$ & $48.4 \pm 4.1$ & $40.6-57.3$ \\
\hline & Hispanic & $6.9 \pm 1.7$ & $3.6-11.6$ & $53.3 \pm 4.4$ & $42.8-63.4$ \\
\hline & Total & $7.2 \pm 1.7$ & $3.6-13.2$ & $51.0 \pm 5.2$ & $39.5-67.1$ \\
\hline \multirow[t]{5}{*}{ L2 } & Black & $7.9 \pm 1.7$ & $5.1-13$ & $49.1 \pm 4.2$ & $38.6-59.5$ \\
\hline & White & $7.6 \pm 1.7$ & $4.8-12.9$ & $55.4 \pm 4.0$ & $46.7-64.3$ \\
\hline & Asian & $7.2 \pm 1.5$ & $4.6-11.8$ & $49.1 \pm 4.4$ & $41.0-63.9$ \\
\hline & Hispanic & $7.4 \pm 1.5$ & $4.7-11.5$ & $53.6 \pm 4.0$ & $45.3-61.9$ \\
\hline & Total & $7.6 \pm 1.6$ & $4.6-13$ & $51.5 \pm 5.0$ & $38.6-64.3$ \\
\hline \multirow[t]{5}{*}{ L3 } & Black & $9.5 \pm 1.8$ & $5.5-16.2$ & $48.8 \pm 4.4$ & $38.6-59.8$ \\
\hline & White & $9.3 \pm 1.8$ & $6.0-14.8$ & $54.0 \pm 4.0$ & $46.2-64.3$ \\
\hline & Asian & $8.8 \pm 1.6$ & $5.3-12.6$ & $48.8 \pm 4.2$ & $41.9-61.3$ \\
\hline & Hispanic & $9.0 \pm 1.8$ & $5.6-14.4$ & $52.6 \pm 4.0$ & $42.4-62.6$ \\
\hline & Total & $9.2 \pm 1.8$ & $5.3-16.2$ & $50.8 \pm 4.8$ & $38.6-64.3$ \\
\hline \multirow[t]{5}{*}{ L4 } & Black & $11.2 \pm 1.8$ & $6.7-15.5$ & $47.4 \pm 4.2$ & $37.6-60.7$ \\
\hline & White & $11.4 \pm 1.9$ & $7.1-15.7$ & $51.5 \pm 3.9$ & $43.2-60.4$ \\
\hline & Asian & $10.5 \pm 1.6$ & $7.2-15.2$ & $47.1 \pm 4.0$ & $40.5-59.7$ \\
\hline & Hispanic & $11.0 \pm 2.0$ & $7.5-16.2$ & $50.6 \pm 4.0$ & $42.2-60$ \\
\hline & Total & $11.1 \pm 1.8$ & $6.7-16.2$ & $49.0 \pm 4.5$ & $37.6-60.7$ \\
\hline \multirow[t]{5}{*}{ L5 } & Black & $14.7 \pm 2.1$ & $10.1-20.2$ & $47.1 \pm 5.4$ & $17.9-58.6$ \\
\hline & White & $15.2 \pm 2.0$ & $10.9-20.5$ & $50.8 \pm 3.8$ & 41.9-61 \\
\hline & Asian & $14.1 \pm 1.9$ & $9.7-19.2$ & $45.7 \pm 3.9$ & $39.6-56.9$ \\
\hline & Hispanic & $14.6 \pm 2.5$ & $10.1-20.7$ & $48.9 \pm 3.7$ & $42.4-58$ \\
\hline & Total & $14.7 \pm 2.1$ & $9.7-19.2$ & $48.1 \pm 4.8$ & $17.9-61$ \\
\hline \multirow[t]{5}{*}{ All Pedicles } & Black & $10.2 \pm 1.6$ & $6.5-15.2$ & $48.1 \pm 3.8$ & $39.1-58.3$ \\
\hline & White & $10.1 \pm 1.6$ & $6.7-14.9$ & $53.4 \pm 3.5$ & $45.7-63.4$ \\
\hline & Asian & $9.4 \pm 1.4$ & $6.8-13.5$ & $47.8 \pm 3.9$ & $40.8-58.8$ \\
\hline & Hispanic & $9.8 \pm 1.8$ & $6.9-14.6$ & $51.8 \pm 3.7$ & $43.8-59.7$ \\
\hline & Total & $9.9 \pm 1.6$ & $6.5-15.2$ & $50.1 \pm 4.4$ & $39.1-63.4$ \\
\hline
\end{tabular}


Table 4. Analysis of covariance with post hoc pairwise comparisons of pedicle widths between races controlling for differences in age, weight, and body mass index. Dunn-Bonferroni corrections were applied.

\begin{tabular}{llcccc}
\hline Race (A) & Race (B) & $\begin{array}{c}\text { Mean } \\
\text { Difference } \\
\text { (A-B) }\end{array}$ & $\boldsymbol{P}$ & $\begin{array}{c}\text { Lower Bound } \\
\mathbf{9 5 \%} \text { CI }\end{array}$ & $\begin{array}{c}\text { Upper Bound } \\
\mathbf{9 5 \%} \text { CI }\end{array}$ \\
\hline \multirow{2}{*}{ Black } & White & 0.3 & .706 & -0.2 & 0.8 \\
& Asian & 0.8 & $<.001^{\mathrm{a}}$ & 0.3 & 1.3 \\
& Hispanic & 0.2 & 1.000 & -0.4 & 0.7 \\
\multirow{6}{*}{ Asian } & Black & -0.3 & .706 & -0.8 & 0.2 \\
& Asian & 0.5 & .158 & -0.1 & 1.1 \\
& Hispanic & -0.1 & 1.000 & -0.7 & 0.5 \\
& Black & -0.8 & $<.001^{\mathrm{a}}$ & -1.3 & -0.3 \\
& White & -0.5 & .158 & -1.1 & 0.1 \\
& Hispanic & -0.6 & $.047^{\mathrm{a}}$ & -1.3 & 0.0 \\
& Black & -0.2 & 1.000 & -0.7 & 0.4 \\
& White & 0.1 & 1.000 & -0.5 & 0.7 \\
& Asian & 0.6 & $.047^{\mathrm{a}}$ & 0.0 & 1.3 \\
\hline
\end{tabular}

Abbreviation: CI, confidence interval.

${ }^{\text {a }}$ Significant: $P<.05$.

ANCOVA and Dunn-Bonferroni correction showed that the average EPSL was found to be largest in the White and Hispanic population compared to Blacks and Asians (Table 5). The Black and Asian population had the shortest EPSL at all levels when compared to Whites and Hispanic (Table 5).

Analysis of the range of EPSL among races demonstrated that the Black population had the smallest measurement for EPSL at all levels from L1 to L5, with the smallest EPSL measuring $<40 \mathrm{~mm}$ for each level. (Table 3). The White population was found to have the largest EPSL measurement at all levels, each level having the largest EPSL measurement of $>60 \mathrm{~mm}$ (Table 3).

\section{DISCUSSION}

The importance of understanding individual pedicle anatomy to assist in proper pedicle screw sizing cannot be overstated. It has been demonstrated that a larger diameter and longer pedicle screws have greater pullout strength. ${ }^{13,14}$ However, choosing a screw that is too wide can purchase and possibly fracture the cortical wall, risking nerve root injury. ${ }^{2}$ Furthermore, choosing a screw that is too long can encroach or even perforate major structures such as the aorta, and the common iliac artery and vein. The misplacement rate varies depending on the literature and has been reported as high as $30 \%$, with the majority being asymptomatic. ${ }^{15}$ Sarwahi et $\mathrm{al}^{15}$ examined the safest limits of anterior or anterolaterally misplaced screws. They determined that screws adjacent to or impinging the aorta protruded an average of $5.7 \mathrm{~mm}$, whereas screws not involving the aorta breached an average
Table 5. Analysis of covariance with post hoc pairwise comparisons of pedicle lengths between races controlling for differences in age, weight, and body mass index. Dunn-Bonferroni corrections were applied.

\begin{tabular}{llrccc}
\hline Race (A) & Race (B) & $\begin{array}{c}\text { Mean } \\
\text { Difference } \\
\text { (A-B) }\end{array}$ & $\boldsymbol{P}$ & $\begin{array}{c}\text { Lower Bound } \\
\mathbf{9 5 \%} \text { CI }\end{array}$ & $\begin{array}{c}\text { Upper Bound } \\
\mathbf{9 5 \%} \text { CI }\end{array}$ \\
\hline \multirow{2}{*}{ Black } & White & -4.6 & $<.001^{\mathrm{a}}$ & -5.7 & -3.4 \\
& Asian & 0.2 & 1.000 & -1.0 & 1.4 \\
\multirow{6}{*}{ White } & Hispanic & -4.4 & $<.001^{\mathrm{a}}$ & -5.7 & -3.1 \\
& Black & 4.6 & $<.001^{\mathrm{a}}$ & 3.4 & 5.7 \\
& Asian & 4.8 & $<.001^{\mathrm{a}}$ & 3.5 & 6.1 \\
& Hispanic & 0.2 & 1.000 & -1.2 & 1.6 \\
\multirow{6}{*}{ Hispan } & Black & -0.2 & 1.000 & -1.4 & 1.0 \\
& White & -4.8 & $<.001^{\mathrm{a}}$ & -6.1 & -3.5 \\
& Hispanic & -4.6 & $<.001^{\mathrm{a}}$ & -6.0 & -3.2 \\
& Black & 4.4 & $<.001^{\mathrm{a}}$ & 3.1 & 5.7 \\
& White & -0.2 & 1.000 & -1.6 & 1.2 \\
& Asian & 4.6 & $<.001^{\mathrm{a}}$ & 3.2 & 6.0 \\
\hline
\end{tabular}

Abbreviation: CI, confidence interval.

${ }^{\mathrm{a}}$ Significant: $P<.05$.

of $3.9 \mathrm{~mm}$. Therefore, an understanding of the maximum safe pedicle screw diameter and screw length can greatly aid in reducing failure and other complications.

Preoperative analysis of exact PD and EPSL is extremely important. It was therefore the goal of this investigation to supplement preoperative and intraoperative methods of pedicle assessment. The data obtained in this anatomical study might allow surgeons to more closely gauge appropriate screw size, given this additional demographic information.

Image guidance and robotic assistance is becoming more widespread in its utilization and can be an invaluable intraoperative adjunct during spinal fusion with pedicle screw insertion. Main advantages of this technique are increased accuracy, decreased malposition, and decreased radiation exposure to the patient, as well as the surgeon. ${ }^{16,17}$ Therefore, one may argue that preoperative planning does not need to be done, and screw width and length can be measured intraoperatively. Although navigation-assisted surgery is gaining popularity because of its precision and reliability, it is still expensive, has not been globally adopted, and has been found to be less accurate in the lumbar spine. ${ }^{18-20}$ Balling et $\mathrm{al}^{19}$ recently examined 1547 pedicle screws from $\mathrm{T} 10$ to $\mathrm{S} 1$ to determine the extent of misplacement using navigated-assisted insertion. They found that the highest amount of screw misplacement was in the lumbosacral spine, and the most common reason for screw revision was improper depth. Waschke et $\mathrm{al}^{20}$ also concluded that navigation assistance was less accurate in the lumbar spine when compared to freehand technique. One of the main conclusions to be drawn 
from this study is the importance of preoperative planning and intraoperative adjustments in instrumented spinal surgery. Although one can attain a better sense from this research of PD and EPSL based on the race of the patient, there is still considerable variability.

This multicenter study demonstrated that the Black and Asian populations consistently had significantly shorter EPSL in the lumbar spine than the Hispanic or White populations. Currently these are the only data analyzing EPSL among different races. Our study also demonstrated that there was a significant difference in PD between races. This data supports Albano et $\mathrm{al}^{3}$ who also concluded significant PD variability between races in the lumbar spine. They examined transverse outer cortical PD in the lumbar spine on CT scans on coronal cuts between various races. They concluded that the Asian population had significantly smaller PD than Whites and Blacks. Simpson et $\mathrm{al}^{9}$ determined that the outer cortical pedicle width measurement on the coronal view alone could overestimate the true pedicle width. Our data demonstrate that measuring transverse outer cortical PD on the coronal- and axial-cut CT scans are a reliable method for determining pedicle screw width.

In the age of cost-conscious medical care, the use of expensive diagnostic imaging studies is becoming less favorable. On the basis of these results, however, we support previous research recommending the use of preoperative CT scans for pedicle screw templating as the safest method of inserting pedicle screws with the greatest pullout strength. Although preoperative CT scans may lead to increased costs in the appropriately selected patients, and necessitates each patient be subject to increased radiation exposure, ${ }^{21,22}$ we suggest that the importance of preoperative pedicle analysis highly outweighs these issues. Notwithstanding this assertion, while there may still be a role for preoperative CT scans in the more complex and dysplastic patients, the cost benefit for routine procedures where only a few pedicle screws will be used may not be practical. Data like these, and the demographic data we observed, can allow surgeons to make a more informed decision based on x-ray images. There may still be a role for supplementary CT scans in addition to these findings, but we hope to provide a clearer picture of reproducible guidelines among certain populations. Our data regarding average PD and EPSL could aid surgeons in proper estimation and selection of correct pedicle screw size, potentially limiting intraoperative complications and improving patient outcomes.

Due to our large sample size, an analysis of estimated marginal means depicts narrow confidence intervals and thus validates that our results are highly representative of these different races. Our study is significantly strengthened by our large sample size from multiple hospitals over a diverse geographic area, thereby allowing our results to be generalizable among patient geographic populations. Other strengths of the study include that the data were obtained by a single observer and were confirmed by a more senior physician, therefore enhancing reliability with respect to interobserver variability.

Limitations of the study include not standardizing the position of the patient on the CT scanner. Our study further reinforced this concept when we compare our outer cortical transverse PD on the axial view compared with that of Albano et $\mathrm{al}^{3}$ on the coronal view. Notwithstanding, our sample size was sufficiently large, thereby ensuring a strong representation of true values. There was also variability in the size of the $\mathrm{CT}$ scan cuts used at different hospitals, which could mislead us as to the true midpoint of the pedicle isthmus. However, based on the retrospective nature of this study, we were unable to control this variable. Another limitation of this study is the increased difficulty in accurately assessing PD and pedicle screw length in the lower lumbar spine in the arthritic elderly patient. However, this difficulty would be reflected in obtaining any measurements outside of this study and would therefore strengthen the validity of our results. Also, the measurements were not repeated by the other readers and averaged; this could have improved the validity of our measurements. We also understand that other variables such as age, BMI, and sex can play a role in pedicle anatomy, which we addressed using ANCOVA. However, given the retrospective analysis of the study, only $65 \%$ of data points for height, weight, and BMI were complete among each patient.

\section{CONCLUSION}

This study demonstrates that there are significant differences in pedicle morphology among races that must be taken into consideration when inserting pedicle screws during lumbar spinal fusion. Knowledge of these differences is of the utmost importance 
in order to limit complications while improving fixation.

\section{REFERENCES}

1. Woo EJ, Dicuccio MN. Clinically significant pedicle screw malposition is an underestimated cause of radiculopathy. Spine J. 2018;18(7):1166-1171. doi:10.1016/j.spinee.2017.11.006

2. Brantley AG, Mayfield JK, Koeneman JB, et al. The effects of pedicle screw fit. An in vitro study. Spine. 1994;19(15):1752-1758.

3. Albano J, Lentz J, Stockton R, et al. 2019 Demographic analysis of lumbar pedicle diameters in a diverse population. Asian Spine J. 2019;13(3):410-416. doi:10.31616/asj.2018.0195

4. Stockton R, Albano J, Lentz J, Ganz M, Grewal K, Katsigiorgis G. A comparison of lumbar transverse pedicle angles between ethnic groups: a retrospective review. $B M C$ Musculoskelet Disord. 2019;20(1). doi:10.1186/s12891-019-25072

5. Yusof MI, Ming LK, Abdullah MS, Yusof AH. Computerized tomographic measurement of the cervical pedicles diameter in a Malaysian population and the feasibility for transpedicular fixation. Spine (Phila Pa 1976). 2006;31(8):E221-E224.

6. Tse MS, Chan CH, Wong KK, Wong WC. Quantitative anatomy of $\mathrm{C} 7$ vertebra in southern Chinese for insertion of lateral mass screws and pedicle screws. Asian Spine $J$. 2016;10(4):705-710.

7. Christodoulou AG, Apostolou T, Ploumis A, Terzidis I, Hantzokos I, Pournaras J. Pedicle dimensions of the thoracic and lumbar vertebrae in the Greek population. Clin Anat. 2005;18(6):404-408.

8. Singel TC, Patel MM, Gohil DV. A study of width and height of lumbar pedicles in Saurashtra region. J Anat Soc India. 2004;53(1):4-9.

9. Simpson V, Clair B, Ordway NR, Albanese SA, Lavelle WF. Are traditional radiographic methods accurate predictors of pedicle morphology? Spine (Phila Pa 1976). 2016;41(22):1740-1746.

10. Bjerke, BT, Zarrabian M, Aleem IS, Fogelson JL, et al. Incidence of osteoporosis-related complications following posterior lumbar fusion. Glob Spine J. 2017;8(6)563-569. doi: $10.1177 / 2192568217743727$

11. Halvorson TL, Kelley LA, Thomas KA, et al. Effects of bone mineral density on pedicle screw fixation. Spine. 1994;19(21):2415-2420.

12. Misenhimer GR, Peek RD, Wiltse LL, Rothman SL, Widell EH Jr. Anatomic analysis of pedicle cortical and cancellous diameter as related to screw size. Spine (Phila Pa 1976). 1989;14(4):367-372.

13. Bianco R-J, Arnoux PJ, Wagnac E, Mac-Thiong J-M, Aubin CÉ. Minimizing pedicle screw pullout risks. Clin Spine Surg. 2017;30(3). doi:10.1097/bsd.0000000000000151

14. Karami KJ, Buckenmeyer LE, Kiapour AM, Kelkar PS,
Goel VK, Demetropoulos CK, Soo TM. Biomechanical evaluation of the pedicle screw insertion depth effect on screw stability under cyclic loading and subsequent pullout. J Spinal Disord Tech. 2015;28(3). doi:10.1097/bsd.0000000000000178

15. Sarwahi V, Payares M, Wendolowski S, et al. Pedicle screw safety: how much anterior breach is safe? A cadaveric and CT-based study. Spine. 2017;42(22):E1305-E1310. doi:10.1097/ BRS.0000000000002153

16. Kosmopoulos V, Schizas C. Pedicle screw placement accuracy: a meta-analysis. Spine (Phila Pa 1976). 2007;32(3):E111-E2220.

17. Tjardes T, Shafizadeh S, Rixen D, et al. Image-guided spine surgery: state of the art and future directions. Eur Spine J 2010;19(1):25-45.

18. Ringel F, Stoffel M, Stüer C, Meyer B. Minimally invasive transmuscular pedicle screw fixation of the thoracic and lumbar spine. Operat Neurosurg. 2006;59(suppl 4):361-367.

19. Balling $\mathrm{H}$, Blattert TR. Rate and mode of screw misplacements after 3D-fluoroscopy navigation-assisted insertion and 3D-imaging control of 1547 pedicle screws in spinal levels T10-S1 related to vertebrae and spinal sections. Eur Spine J. 2017;26(11):2898-2905. doi:10.1007/s00586-017-5108-5

20. Waschke A, Walter J, Duenisch P, Reichart, R., Kalff, R., \& Ewald, C. CT-navigation versus fluoroscopy-guided placement of pedicle screws at the thoracolumbar spine: single center experience of 4,500 screws. Eur Spine J. 2013;22(3):654 660 .

21. Smith-Bindman R, Lipson J, Marcus R, et al. Radiation dose associated with common computed tomography examinations and the associated lifetime attributable risk of cancer. Arch Intern Med. 2009;169(22):2078-2086.

22. Berrington de González A, Mahesh M, et al. Projected cancer risks from computed tomographic scans performed in the United States in 2007. Arch Intern Med. 2009;169(22):20712077.

Disclosures and COI: The authors received no funding for this study and report no conflicts of interest.

Corresponding Author: Brandon Petrone, DO, Department of Orthopedic Surgery, Northwell Health Plainview Hospital, 888 Old Country Road, Plainview, NY 11803. Phone: (570) 369-6279; Email: bop03862@gmail.com.

\section{Published 16 April 2021}

This manuscript is generously published free of charge by ISASS, the International Society for the Advancement of Spine Surgery. Copyright (c) 2021 ISASS. To see more or order reprints or permissions, see http://ijssurgery.com. 